\title{
A FI-STAR Approach to the Purchasing Power Parity in the North African Countries
}

\author{
Abdelhak BENAMAR \\ Faculty of economics and management, University of Tlemcen- Algeria \\ E-mail: benamarabdelhak@yahoo.fr \\ Kamel AIT ZIANE \\ Institute of economics, University of Khemis Miliana, Algeria \\ E-mail: kaitziane@yahoo.fr \\ Houria AMIMI \\ Institute of economics, University of Khemis Miliana, Algeria \\ Email: haitziane@yahoo.fr \\ Mohamed BENBOUZIANE \\ Faculty of economics and management, University of Tlemcen- Algeria \\ E-mail: mbenbouziane@yahoo.fr
}

\begin{abstract}
The main objective of this paper is to test the validity of the purchasing power parity in the North African countries. Earlier studies have used either nonlinear models or Long Memory (ARFIMA) process to look for the unit-root properties of the exchange rate behaviour. While the use of each technique independently can in some cases be favourable for the PPP hypothesis, it has failed in others. This is why recently the joint hypothesis of long memory and stochastic regime switching models has been developed. In fact, empirical evidence has shown that the two modelling techniques can be intimately linked. In this paper we will be using the FISTAR model proposed by van Dijk, Franses and Paap (2002) is order to test the validity of PPP. Several major findings have been raised from our study. The results show that the joint hypothesis of long memory and nonlinearity is not accepted in all our North African exchange rates. In fact, the behaviour is shown to be nonlinear. The results also show that the purchasing power parity could not be accepted in the case of Tunisia. We found that there is no evidence of long memory in the cases of Algeria and Egypt. Moreover, the study has shown that when using ESTAR model alone, this can lead to some misinterpretation of the real exchange rate behaviour in many cases. This is why it is necessary to use the FI-STAR model which would give more information to policy makers to face exchange rate shocks, especially, when these shocks are characterised by a long memory process.
\end{abstract}

Keywords: Purchasing Power Parity (PPP) -ARFIMA Models- FISTAR- Stationarity- North African countries

\section{Introduction}

The Purchasing Power Parity (PPP) concept is one of the oldest and most controversial relationships in the theory of exchange rates. Although the term "purchasing power parity» was coined by Cassel (1918). it has a very much longer history in economics (See, Frenkel, 1978). It is also one of the most widely tested economic hypotheses. PPP is based on the law of one price (LOOP) and implies that exchange rates should equalize the national price levels of different countries in terms of a common currency. Although Long run PPP is a very simple proposition about exchange rate behaviour, it has attracted the attention of researchers for a long time. Indeed, it has been viewed as basis for international comparison of income and expenditures, an efficient arbitrage condition in goods and assets, an equilibrium condition, and a theory of exchange rate determination (Officier ,1976; Frenkel, 1978; Dornbush, 1987; Isard, 1978; Breuer, 1994; Froot and Rogoff, 1995; Taylor, 1995; Rogoff, 1996; Sarno and Taylor, 2001).

Many studies in international finance have examined the validity of PPP over the long run either by testing whether nominal rates and relative prices move together in the long run or by testing whether the real exchange rate has a tendency 
to revert to a stable equilibrium level over time. These studies have yielded different result outcomes depending of the testing procedures employed.

Moreover, the empirical literature on Purchasing Power Parity seems to have arrived at the consensus that real exchange rates tend toward PPP in the very long run. However, as Rogoff (1996) points out, the slow rate of convergence to PPP, with deviations having a half life about three to five years, remains a puzzle.

New developments in PPP extend the traditional approaches in two important ways. First, they recognize the nonlinearities created by information, transaction and transportation costs, and other trade impediments. This new approach refers to the modern theories of LOP and PPP (Peppinger, 2004). The nonlinearity helps resolve a number of puzzles concerning the persistence and volatility of real exchange rates. The time series models that are considered for describing and forecasting nonlinear properties of different macroeconomic variables (such as, exchange rates, unemployment...) are either Markov switching type, see Hamilton (1989). or the Threshold autoregressive [TAR], see Tong (1990). Sekkioua (2005). or Smooth Transition Autoregressive type, see Granger and Terasvirta (1993) and Franses, Van Dijk and Terasvirta (1993). The second issue that is raised by PPP literature is that shocks to exchange rate series seem rather persistent. This feature is commonly coined as the Long Memory feature; see Diebold and Rudebush (1989). and Baillie, R. (1996). The model that is used to describe such a feature belongs to the class of the Fractionally Integrated [FI] time series models; see Granger and Joyeux (1980) and Hosking (1981).

A number of empirical studies support either a non-linear adjustment of real exchange rates toward long-run equilibrium or long memory behaviour to exchange rates. However, very few are the attempts to combine he two features (long memory and nonlinearity) in one single model, see Van Dijk, Franses and Paap (2002) and Smallwood (2005).

Many recent studies have found strong evidence of complementarity and substitutability between long memory and nonlinear models. So, it would be rather useful to try to capture both features in one single model. In this paper we put forward such a model. Thus, we will be using the FISTAR model as proposed by van Dijk, et al (2002) in order to test the validity of the PPP in the North African countries

The rest of the article is structured as follows. In the next section we provide a short review on empirical validity of the PPP. Section 3 discusses the FISTAR methodology. Section 4 describes the data. The results are reported in section 5. A final section briefly summaries and concludes.

\section{Empirical evidence on PPP}

\subsection{Theoretical basis on PPP}

The Purchasing Power Parity (PPP) concept is one of the oldest and most controversial relationships in the theory of exchange rates. Among the most popular versions of PPP, there exist the "absolute" version which states that the exchange rate between two currencies of any pair of countries should equal the ratio of the aggregate price levels in the two currencies, and the "strict" version which relates changes in exchange rates to in inflation differential rates.

The earlier promises of the flexible exchange rates were that long-run trends in exchange markets would be denominated by relative rates of inflation, i.e. that exchange rates would follow the PPP (Friedman, 1953). and that temporary factors such as shifting interest rates might cause temporary deviations from PPP but such deviations are reduced because speculators force the market towards its long long-run equilibrium.

The two mentioned versions can be written as follows:

Absolute Version

$$
\ln S_{t}=a+b \ln \left(p / p^{*}\right)_{t}+U_{t}
$$

Relative Version

$$
\Delta \ln S_{t}=b \Delta \ln \left(p / p^{*}\right)+V_{t}
$$

Where $\quad S_{\mathrm{t}}=$ the exchange rate

$\left(p / p^{*}\right)=$ the ratio of domestic to foreign price indices, the asterisk denotes the foreign country.

$U_{t}, V_{t}=$ error terms

$$
\begin{aligned}
& \Delta=\text { the first difference operator } \\
& \mathrm{a}=\text { the intercept term } \\
& \mathrm{b}=\text { the slope coefficient. }
\end{aligned}
$$

There is not, however, a unique view about which price index should be used in these versions. According to one extreme view, exchange rates should be held in line with general price indices, i.e. prices of both traded and non-traded goods. Advocates of this view emphasise the role of asset equilibrium in determining the exchange rate (Cassel, 1930). A second view focuses on commodity arbitrage as the international mechanism that correct purchasing power disparities 
and therefore argues that only prices of traded goods should be included in the calculation of the ratio of price indices. Supporters of this view are, for example, (Bunting, 1939; Hecksher, 1930; Pigou, 1920; Viner, 1937).

The third view goes further to account for non-traded goods only. According to Keynes, the use of prices of traded goods only, is no more than a tautology; because it simply means that the price of a commodity must be the same elsewhere when converted into a common currency. Hansen and Hodrick (1980) for example claimed for the use of production indices.

The choice of the price index is not the only deficiency to the PPP, other factors such as the choice of base period for relative PPP and the transportation costs may also bias the calculation of PPP. These deficiencies have weakened the theoretical basis of PPP.

The PPP doctrine is seen as an equilibrium relationship between an exchange rate and some designated ratio of price indices. This relationship implies that any divergence from the ratio will set in motion corrective forces acting to restore equilibrium. The question that can be asked here is which causes which? Is it the changes in prices that cause exchange rate movements or is it the opposite?

The majority of authors recognised that prices and exchanges rates are determined simultaneously. A minority, however, argued that there exists a causal relationship between prices and exchange rates. Cassel (1930). for example, claimed that the causality goes from prices to the exchange rate; Einzig (1937) claimed the opposite.

\subsection{Violations of PPP}

This section considers some empirical results concerning the validity of purchasing power parity. The body of empirical literature on PPP (Purchasing Power Parity) focused on developing countries is quite thin, both in absolute terms and when compared to that available for industrial economies (Breuer, 1994). This is probably a consequence of the developing countries' reluctance to adopt floating exchange rates following the breakdown of the Bretton Woods system. Indeed, the fact that the majority of these countries held on for a while to fixed exchange rate arrangements-as well as to all forms of restrictions on current and capital account transactions-made it both less pressing and less meaningful to use their data to test models that relied upon (or consisted of) PPP-based notions of the equilibrium exchange rate.

The situation started to change in the late 1980s. Since then, a growing number of studies have examined the time series properties of RER in various developing countries, in many cases testing explicitly for some version of PPP.

To classify the tests employed in the studies we followed the demarcation of the various stages of tests of PPP proposed by Breuer, 1994 and Froot and Rogoff, 1995, namely: simple tests of PPP as the null hypothesis, univariate tests of the time series properties of the RER series, and cointegrating tests of PPP, both bivariate and trivariate .

The results given by these studies capture some interesting features of empirical studies of RER and PPP in emerging economies. First, in terms of coverage, there is far more evidence available for Latin American economies than for developing countries in other parts of the world. Second, the periods covered by the studies are quite short. The majority of studies conducted tests on data series that covered less than 30 years and some of them did so on series that covered less than 15 years. Third, studies relied a bit more heavily on consumer price indices than on wholesale price indices to construct their measure of relative (domestic to foreign) prices. Fourth, the majority of studies relied on some type of univariate test to examine the main properties of the RER and the hypothesis. Only very few studies (McNown and Wallace, 1989, Liu, 1992, Gan, 1994 and Seabra, 1995) conducted bivariate cointegrating tests of PPP. And fifth, studies were generally unclear about the precise PPP hypothesis that was being tested.

An obvious consequence of the predominance of univariate tests of PPP is that the bulk of the findings obtained by the above studies revolve around the stationarity of various measures of the RER. By and large, the hypothesis that the RER is stationary in developing countries (and, thus, that some form of PPP condition holds in the long run) does not receive much support from these studies. In fact, Edwards, 1989 tested the random walk hypothesis for a combined total of 44 series, and rejected it in about $2 / 3$ of the cases.

Results from the (few) studies that used cointegration tests were somewhat more supportive of the PPP hypotheses. The two studies that conducted trivariate tests of cointegration (Liu, 1992 and Seabra, 1995) found even stronger evidence of an equilibrium relationship between the exchange rate and domestic and foreign prices (18 of 20 cases). Notably, all the support for PPP obtained from these stage-three tests stemmed from data on Latin American countries; in fact, Gan, 1994 did not find evidence of cointegration between the exchange rate and prices in any of the five East Asian countries in his sample.

Seeing what the studies have to offer, one gets the distinct feeling that our knowledge of the basic time series properties of RER in developing countries and, in particular, of the relevance of PPP as a long-run benchmark for the equilibrium RER in these economies is fairly rudimentary. The most serious shortcoming is, without question, the low power of the tests (especially of cointegration tests) to distinguish among alternative hypotheses in the short periods covered by the studies a deficiency that cannot be fixed by the common practice of increasing the number of observations through the use of 
quarterly or monthly data (Froot and Rogoff, 1995, Oh, 1996). But this is hardly the only problem. The pervasive and severe data problems that one encounters in developing countries may well be at the root of these shortcomings, and it is quite possible that for many countries this constraint will not disappear for many years. But this does not alter the basic conclusion that the evidence on RER stationarity and long-run PPP contained in studies of individual developing countries does not enable us to discern which, if any, of the regularities of the long-run RER that have been found for industrial economies are also applicable to (or relevant for) the developing world.

\subsection{Recent developments in PPP violations}

Among the possible explanations for the violation of the law of one price and the purchasing power parity suggested by the empirical evidence, transportation costs, tariffs and non-tariff barriers are dominant. This has given rise to theoretical models of non-linear exchange rate arrangements (e.g. Williams and Wright, 1991; Dumas, 1992; Sercu, Uppal and van Hulle, 1995, Sarno and Taylor, 2001). To test these models empirically Michael, Nobay, and Peel (1997) use the Lothian and Taylor (1996) long span of annual data on dollar-sterling and franc-sterling exchange rates as well as monthly data for three real exchange rates during the interwar period and show that statistically significant nonlinearity characterizes the adjustment toward equilibrium of the real exchange rate series examined, successfully modeled as exponential smooth-transition autoregressive processes (Granger and Terasvirta, 1993). Obsfeld and Taylor (1997) investigated for the nonlinear nature of the adjustment process in term of threshold autoregressive (TAR) model (Tong, 1990). Obsfeld and Taylor provide evidence that TAR models work well when applied to disaggregated data, and yield estimates in which the thresholds correspond to popular rough estimates of the order of magnitude of actual transport costs (Sarno and Taylor, 2002).

As described earlier, a new issue has been raised in the PPP literature and is concerned by the fact that shocks to exchange rate series seem rather persistent, giving rise to a new exchange rate terminology called Long Memory models. A lot of empirical studies have used these models. The latter have tested the fractionally integrated time series. Among the pioneers, we find Baillie, R.T., Bollerslev, T., (1994). Baillie, R.T., Chung, C.F., Tieslau, M.A., (1996). Baillie, R.T.; Bollerslev, T.; Mikkelsen, H.O. (1996) and Baillie, Richard T. (1996).

As far as developing countries are concerned, Taylor and Sarno (2001) examined the behaviour of the real exchange rates of nine transition economies (Bulgaria, the Czech Republic, Hungary, Latvia, Lithuania, Poland, Romania, the Slovak Republic, and Slovenia) during the1990s. They used a nonlinear multivariate generalization of the Beveridge-Nelson decomposition. They results were supportive to the nonlinear behaviour of real exchange rates. However, and to the best of our knowledge, no empirical work has been carried out to test the nonlinearity and long memory of exchange rates in the North African countries.

\section{A Long Memory Nonlinear Model}

In this section, we introduce a methodology that give us the opportunity to test for both non-linearity and long memory simultaneously. We shall start first by Long memory models.

\subsection{Long Memory Models (ARFIMA)}

The concept of Long memory was known since work on fractional integration given by Granger and Joyeux (1980). They have found that the spectral density function of the differenced process appeared to be over-differenced, while the level of the series exhibited long run dependence that was inconsistent with stationary ARMA dynamics, Smallwood, 2005). They proposed a use of a fractional differencing operator that could produce a stationary ARMA series.

According to Granger (1980). Granger and Joyeux (1980) and Hosking (1981). the ARFIMA (p, d, q) model can be defined as:

$$
\phi(L)(1-L)^{d}\left(y_{t}-u\right)=\theta(L) \varepsilon_{t}
$$

with $E\left(\varepsilon_{t}\right)=0 ; E\left(\varepsilon_{t}^{2}\right)=\sigma^{2}$ and $E\left(\varepsilon_{t} \varepsilon_{s}\right)=0$ for $t \neq s ; \phi(L)=\left(1-\phi_{1} L-\ldots-\phi_{p} L^{p}\right)$ and $\theta(L)=\left(1+\theta_{1} L+\ldots+\theta_{q} L^{q}\right)$

have all roots lying outside the unit circle, $\mathrm{d}$ is any real number; $(1-L)^{d}$ is the differencing operator and can be defined as :

$$
(1-L)^{d}=\sum_{k=1}^{\infty} \frac{\Gamma(k-d)}{\Gamma(-d) \Gamma(k+1)} L^{k}
$$


With $\Gamma()$ is the gamma or generalised factorial function.

For $-0.5<\mathrm{d}<0.5$, the process is stationary and invertible, and $y_{t}$ is said to be fractionally integrated of order $\mathrm{d}(\mathrm{i} . \mathrm{e} .: \mathrm{I}(\mathrm{d}))$. Thus d represents the degree of long memory behaviour. For $\mathrm{d}<1$, the impulse response weights are finite, witch implies that shocks to the level of the series are mean reverting (the series are stationary).

\subsection{Non Linear Models (STAR):}

To capture the nonlinear feature of time series, a variety of models can be used (see, Franses \& van Dijk, 2000). but the most popular model is the STAR. This model has been empirically developed by Terasvirta (1994). Generally, the model STAR (p) with two regimes can be written as:

$$
y_{t}=\left(\phi_{1,0}+\phi_{1,1} y_{t-1}+\ldots+\phi_{1, p} y_{t-p}\right)+\left(\phi_{2,0}+\phi_{2,1} y_{t-1}+\ldots+\phi_{2, p} y_{t-p}\right) G\left(s_{t}, \gamma, c\right)+\varepsilon_{t}
$$

With $\varepsilon_{t}$ a gaussian white noise ; $G\left(s_{t}, \gamma, c\right)$ the transition function governing the movement from one regime to another and $S_{t}$ is a function of the transition variable so that: $S_{t}=y_{t-d^{*}}$ According to Taylor, Peel \& Sarno (2001). the transition variable the most sensible is the dependent variable that is lagged one period; the argument $\gamma$, which determines the degree of curvature of the transition function, and the argument $\mathrm{c}$, which is the threshold parameter.

Generally speaking, the transition function could be either a logistic function (resulting in a LSTAR). or an exponential function (resulting in an ESTAR). Smallwood (2005) argued that the logistic function is preferred when asymmetric behavior is expected in the transition variable in order to distinguish between the expansion and recessions periods, (van Dijk, Terasvirta \& Franses, 2002). However, Taylor, Peel \& Sarno (2001) argued that the logistic function (LSTAR) is inappropriate for modelling exchange rate movements. According to them, there exist no economic reasons why exchange rtes adjust above or below the equilibrium. Thus, symmetric transition function is more appropriate. This is why, we have chosen to use an exponential transition function.

The exponential transition function can be written as follows:

$$
G\left(s_{t}, \gamma, c\right)=1-\exp \left[-\gamma\left(s_{t}-c\right)^{2}\right]
$$

This function is asymmetric (It does not depend on the fact that the transition variable move above or below the threshold).

The parameter $\gamma$ controls the degree of nonlinearity. When $\gamma \rightarrow 0$, the transition function tends towards 0 , and the model (2) will be a simple autoregressive model. And when $\gamma \rightarrow \infty$, the transition function will converge towards unity, which implies that the model (2) will be a different autoregressive model with the coefficients equal to the sum of autoregressive coefficients of the two regimes.

In order to test for the nonlinearity in the ESTAR model, we can use two hypotheses, either: $\gamma=0$ or $\phi_{2,0}=\phi_{2,1}=\ldots=\phi_{2, p}=0$. However, the complexity of these tests is due to the fact that the parameters of the ESTAR models are unidentified under the null hypothesis of non linearity (nuisance parameter, Note 1). This problem is circumvented by Luukkonen, Saikkonen \& Terasvirta (1988). They have proposed an approximation of the series by a 
first-order Taylor expansion of the transition function. Après this approximation, the unidentification problem will be less present, and the null hypothesis of linearity can be conveniently tested using Lagrange multiplier (LM) test with a standard asymptotic distribution of $\chi^{2}$ under the null hypothesis.

The development of the first-order Taylor series expansion of the transition function with $\gamma=0$ under the constraint of $d^{*}<p$ can be written as follows:

$$
y_{t}=\sum_{j=1}^{p}\left(\beta_{1,0}+\beta_{1, j} y_{t-j}\right)+\sum_{j=1}^{p}\left(\beta_{2, j} y_{t-j} y_{t-d^{*}}\right)+\sum_{j=1}^{p}\left(\beta_{3, j} y_{t-j} y_{t-d^{*}}^{2}\right)+e_{t}
$$

The terms $\beta_{2,0} y_{t-d}$ and $\beta_{3,0} y_{t-d^{*}}^{2}$ are excluded in order to avoid the problem of multicollinearity (Smallwood, 2005). $e_{t}$ is related to the disturbance $\varepsilon_{t}$ is the remainder from the first-order Taylor series expansion. After this development, the null land alternative hypotheses

$$
\begin{array}{ll}
\mathrm{H} 0: \beta_{2, j}=\beta_{3, j}=0 & \text { with } \mathrm{j}=1, . ., \mathrm{p} \\
\mathrm{H} 1: \beta_{2, j} \neq 0 \text { or } \beta_{3, j} \neq 0 & \text { for at least one } \mathrm{j}
\end{array}
$$

The $\chi^{2}$ version of the LM statistic is calculated as follows :

$$
L M_{\chi^{2}}=\frac{T\left(S S R_{R}-S S R_{U R}\right)}{S S R_{R}}
$$

With $\mathrm{T}$ as the number of usable observations; $S S R_{R}$; is the sum of squared errors calculated under the null hypothesis. This hypothesis is distributed as a $\chi^{2}(2 p)$ statistic.

The $\mathrm{F}$ version of the test can be computed as follows:

$$
L M_{F}=\frac{\left(S S R_{R}-S S R_{U R}\right) / 2 p}{S S R_{U R} /(T-3 p-1)}
$$

And is distributed as an $F(2 p, T-3 p-1)$ statistic.

\subsection{The FI-STAR Model:}

The FI-STAR model has been recently developed by Van Dijk, Franses \& Paap (2002). Generally speaking, the FI-STAR model can be defined as follows:

$$
(1-L)^{d} y_{t}=\left[\phi_{1,0}+\sum_{j=1}^{p} \phi_{1, j}(1-L)^{d} y_{t-j}\right]+\left[\phi_{2,0}+\sum_{j=1}^{p} \phi_{2, j}(1-L)^{d} y_{t-j}\right] G\left(y_{t-d^{*}}, \gamma, c\right)+\varepsilon_{t}
$$

With $\varepsilon_{t}$ is a martingale. In this case, the fractional difference of the time series process is a STAR model.

In their model, Van Dijk, Franses \& Paap (2002) have utilised a logistic transition function (LSTAR). Smallwood (2005). have used merely the same methodology developed by van Dijk \& al. (2002) but using an exponential transition function (ESTAR). Since in the work in hand we will be using an exponential transition function, we will use the methodology developed in Smallwood (2005). 
The problems in the linearity tests in FI-STAR are almost the same as in the STAR models,

After a development of the first-order Taylor transition function (with $d^{*} \leq p$ ) we will have auxiliary function of (4) and can be written as follows

$$
(1-L)^{d} y_{t}=\left[\phi_{1,0}+\sum_{j=1}^{p} \phi_{1, j}(1-L)^{d} y_{t-j}\right]+\left[\sum_{j=1}^{p} \phi_{2, j}(1-L)^{d} y_{t-j} y_{t-d^{*}}\right]+\left[\sum_{j=1}^{p} \phi_{3, j}(1-L)^{d} y_{t-j} y^{2}{ }_{t-d^{*}}\right]+e_{t}
$$

The null hypothesis for nonlinearity is as follows:

$$
\mathrm{H} 0: \phi_{2, j}=\phi_{3, j}=0 \quad, \quad j=1, \ldots, p
$$

Under the null hypothesis, the time series process is distributed as a long memory ARFIMA (p, d, 0). and $e_{t}=\varepsilon_{t}$. To construct the test, we use a conditional likelihood function under the assumption of normality and constant variance. The development of linearity LM test is due to Terasvirta (1994) and van Dijk, Franses \& Paap (2002). First, we estimate an $\operatorname{ARFIMA}(\mathrm{p}, \mathrm{d}, 0)$ model, so that we obtain a residuals series $\hat{\varepsilon}$ and an integration order $\hat{d}$. The residuals sum of squares $\left(S S R_{R}\right)$ is constructed for the residuals $\hat{\varepsilon}$. after that, we estimate a regression on $\hat{\varepsilon}$ for $\sum_{j=1}^{-\sum^{t-1}} \frac{\hat{\varepsilon}_{t-j}}{j}$, $1,(1-L)^{\hat{d}} y_{t-1}, \ldots,(1-L)^{\hat{d}} y_{t-p},(1-L)^{\hat{d}} y_{t-1} y_{t-d^{*}}, \ldots,(1-L)^{\hat{d}} y_{t-p} y_{t-d^{*}}$, and $(1-L)^{\hat{d}} y_{t-1} y_{t-d^{*}}^{2}, \ldots,(1-L)^{\hat{d}} y_{t-p} y^{2}{ }_{t-d^{*}}$. The residuals sum of squares of this regression is denoted $S S R_{U R}$.

The LM test statistic of $\chi^{2}$ and Fisher are calculated as the same method previously described.

The nonlinearity test in the FI-STAR model depends on the estimate value of the differentiation parameter d. To estimate the parameters in a FI-STAR model, van Dijk \& al. (2002) have modified Beran's (1995) approximate maximum likelihood (AML) estimator. The latter is based on an approximation of the LM function, which minimizes the sum of squared residuals for the models ARFIMA (p, d, 0) and FI-STAR (p) :

$$
S(\theta)=\sum_{t=2}^{T} \varepsilon_{t}^{2}(\theta)
$$

With $\theta$ representing the parameters of the two models; the residuals are calculated using equation (4). More precisely, for the FI-ESTAR model, the errors are estimated as follows:

$\varepsilon_{t}=(1-L)^{d} y_{t}-\left[\phi_{1,0}+\sum_{j=1}^{p}(1-L)^{d} y_{t-j}\right]-\left[\phi_{2,0}+\sum_{j=1}^{p}(1-L)^{d} y_{t-j}\right]\left[1-\exp \left\{-\frac{\gamma}{\sigma_{y_{t-d}}^{2}}\left(y_{t-d}-c\right)^{2}\right\}\right]$

To estimate the model, we use a nonlinear least squares methodology, and regarding the difficulties encountered by this joint estimation, van Dijk \& al. (2002) proposed an algorithm that is based on the function of the sum of squares. 
With the exception of the differentiation parameter $\mathrm{d}$, the threshold $\mathrm{c}$ and the smoothness parameter $\gamma$, the FI-STAR model is linear in the remaining parameters. Thus, we could use the nonlinear Least Squares in order to estimate $\gamma$, $c$ and $d$, and the ordinary leas squares to estimate the autoregressive parameters in the two regimes.

In order to assess the validity of the estimation algorithm Smallwood (2005) ran a set of simulations for the FI-STAR specifications. The simulation results are found to be highly supportive of the estimation technique.

\section{Data description}

Monthly data on nominal exchange rates for some selected North African countries (namely, Algeria, Egypt, Morocco and Tunisia) are used in our analysis. The data are obtained from the International Monetary Fund's International Financial Statistics (IFS). Precisely, the sample period the countries under analysis are as follows: It starts from 1974:01 to 2005:05 for Algeria, from 1970:01 to 2005:08 for Morocco, from 1970:01 to 2005:11 for Tunisia and from 1970:01 to 2005:10 for Egypt.

Some data were missing in the middle of the period in many cases. So, we have proceed to some interpolations in order execute model computations.

In our empirical analysis we test the real exchange rate (RER) stationarity. The RER is calculated as follows:

$$
q_{t}=s_{t}-p_{t}+p_{t}^{*}
$$

qt the real exchange rate ;

st the logarithm of nominal exchange rate ;

pt the logarithm of consumer price index of the base country;

$\mathrm{p} * \mathrm{t}$ the logarithm of consumer price index of the foreign country

\section{Estimation results}

\subsection{Estimation of the ARFIMA $(p, d, 0)$ model}

Estimation results of the model ARFIMA (p, d, 0) are in presented in table (1). The number of autoregressive coefficients are determined using AIC and SIC criteria. The Ljung box statistic shows that two of North African countries have a high autocorrelation of errors (Note 2) (Algeria and Tunisia). The results in table (1) show also that with the exception of Morocco, the purchasing power parity hypothesis is accepted. Indeed the standard error at $5 \%$ for Morroco indicates that the estimated value of the $d$ parameter is insignificantly different from unity, implying a rejection of purchasing power parity. In sum, table (1) show that there is no evidence of stationarity (all the d parameters are insignificantly different from zero, and at the same time the autoregressive coefficient is significantly inferior to unity). Thus the results are in favour of a long memory for the majority of countries (Algeria, Egypt and Tunisia,).

\subsection{Nonlinearity tests}

The non linearity test results of the FI-STAR model are presented in table (2). The results show that the linearity hypothesis is rejected at the 5\% level For Algeria and Egypt. For Morocco and Tunisia, this hypothesis is rejected at the $10 \%$ level. Thus, all real exchange rates are non linear. In fact, the results are in favour the FI-STAR model.

\subsection{FI-ESTAR estimation results}

The test results show that the exchange rate behaviour is nonlinear, and more precisely in the form of a FI-ESTAR model. The results are presented in table (3). Smallwood (2005) argued that: "The underlying estimates of the smoothness parameter $\gamma$ are quite large, and as such the estimated Hessian matrix can be volatile. As a consequence, the numerical standard errors are relatively large when compared to table (1)". The results in table (3) show that in the case Tunisia, real exchange rates are found to be nonlinear and highly persistent (It is considered as integrated of order 1). For the remaining countries, real exchange rates are nonlinear and stationary. Thus, they can be represented as ESTAR (p) models.

Other results can be shown in table (3). Such as, for instance, the autoregressive coefficients in the two regimes, the transition function, the threshold, and many other statistics that are used to evaluate the models (e.g., Kurtosis, Skewness, Jarque Bera, Ljung Box, AIC, SCI, SSE). The Ljung Box statistic shows that the problem of autocorrelation is less present in the nonlinear models than ARFIMA models.

However, we have found very difficult to give interpretation to some estimation results presented in table (3) (For instance, the case of nonlinear models without a log memory). The estimation to these models using ESTAR (p) seems to the appropriate solution to this problem.

The test results show, that even though the combination of nonlinear models with long memory models could help us to understand the real exchange behaviour in the North African countries, one could argue that ESTAR models are the most appropriate in the majority of cases. This argument goes in tune with the findings of Sarno and Taylor (2002). Using this 
model, we found that with exception of Tunisia, the purchasing power parity hypothesis is accepted for the remaining North African countries.

\section{Conclusion}

We have tried in this paper to present a new time series model which can test at the same time nonlinearity and long memory. We have applied this model to the real exchange rate in some selected NORTH AFRICAN countries namely (Algeria, Egypt, Morocco and Tunisia). The results show that the joint hypothesis of long memory and nonlinearity is not accepted in all our North African exchange rates. In fact, the behaviour is shown to be nonlinear. The results also show that the purchasing power parity could not be accepted in the case of Tunisia. In fact the series are integrated of order 1. We found that there is no evidence of long memory in the cases of Algeria and Egypt. This last result implies the use of ESTAR models give better results concerning the description of the real exchange rate behaviour in these countries. Moreover, the study has shown that when using ESTAR model alone, this can lead to some misinterpretation of the real exchange rate behaviour in many cases. This is why it is necessary to use the FI-STAR model which would give more information to policy makers to face exchange rate shocks, especially, when these shocks are characterised by a long memory process.

\section{References}

Baillie, R.T., Bollerslev, T. (1994). The long memory of the forward premium. Journal of International Money and Finance 13, 565-571.

Baillie, R.T., Chung, C.F., Tieslau, M.A., 1996. Analysing in inflation by the fractionally integrated ARFIMA-GARCH model. Journal of Applied Econometrics 11, 23-40.

Baillie, R.T.; Bollerslev, T.; Mikkelsen, H.O. (1996). Fractionally Integrated Generalized Autoregressive Conditional Heteroskedasticity. Journal of Econometrics, 74, 3-30.

Baillie, Richard T. (1996) “Long memory processes and fractional integration in econometrics. ” Journal of Econometrics, $73,5-59$.

Beran Jan (1995). "Maximum Likelihood Estimation of the Differencing Parameter for Invertible Short and Long Memory Autoregressive Integrated Moving Average Models", Journal of the Royal Statistical Society. Series B (Methodological). Vol. 57, No. 4. (1995). pp. 659-672.

Breuer, J.B., 1994, “An Assessment of the Evidence on Purchasing Power Parity,” in J. Williamson ed., Estimating Equilibrium Exchange Rates (Washington, DC: Institute for International Economics).

Bunting, F. H. (1939). 'Purchasing Power Parity Theory Reexamined', Southern Economic Journal, 3, 282-301.

Cassel, G. (1930). 'Money and Foreign Exchange after 1919', MacMillan, London.

Cassel, G., (1918). “Abnormal Deviations in International Exchanges,” Economic Journal, Vol. 28, pp. 413-15

Diebold, F.X., and G. Rudebusch. (1989). "Long memory and persistence in aggregate output," Journal of Monetary Economics, 24, 189-209.

Dornbusch, R., 1987, "Purchasing Power Parity," in J. Eatwell, M. Milgate, and P. Newman, eds., The New Palgrave: A Dictionary of Economics (London: Macmillan). pp. 1075-85.

Dumas, B. (1992). "Dynamic equilibrium and the real exchange rate in a spatially separated world." Review of Financial Studies, 5, 153-180.

Edwards, S. (1989). 'Real Exchange Rates, Devaluation and Adjustment: Exchange Rate Policy in Developing Countries', Cambridge, Mass: MIT Press.

Einzig, P. (1937). 'The Theory of Forward Exchange', MacMillan, London.

Franses, P. H., and D., van Dijk (2000). "nonlinear time series models in empirical finance", Cambridge University Press.

Frenkel, J.A., 1978, "Purchasing Power Parity: Doctrinal Perspective and Evidence from the 1920s," Journal of International Economics, Vol. 8, pp. 169-91.

Friedman, Milton, (1953). 'The Case for Flexible Exchange rates', in Essays in Positive Economics, University of Chicago, 157-203.

Froot, K.A., and K. Rogoff, (1995). "Perspectives on PPP and Long-Run Real Exchange Rates," in K. Rogoff and G. Grossman, eds., Handbook of International Economics (Amsterdam: North Holland).

Gan, W.B. (1994). 'Characterizing Real Exchange Rate Behaviour of Selected East Asian Economies', Journal of Economic Development Vol. 19, 2: 67-92

Granger C.W.J., Teräsvirta T. (1993). Modeling Nonlinear Economic Relationships, Oxford University Press, Oxford. 
Granger, C. W. J., and R. Joyeux. (1980) “An introduction to long-memory time series," Journal of Time Series Analysis, $1,15-30$.

Granger, C.W.J. (1980). "Long memory relationships and the aggregation of dynamic models", Journal of Econometrics, Volume: 14, Issue: 2, pp. 227-238.

Hamilton. D.J (1989). "A new approach to the economic analysis of nonstationary times series and the business cycle" Econometrica 57: 357-384.

Hansen, L.P. and Hodrick, R.J. (1980). 'Forward exchange rate as optimal predictor of future spot rates : An econometric analysis', Journal of Political Economy,88 No 5, 829-853.

Hansen B.E. (1996). "Inference When a Nuisance Parameter is not Identified under the Null Hypothesis", Econometrica, 64, 413-430.

Hecksher, E. F. (1930). 'Sweden, Norway, Denmark and Iceland in the World War', New Hawen.

Hosking. Jonathan (1981). "Fractional differencing" Biometrika 68: 167-170.

Isard, P. (1978). 'Exchange Rate Determination: A Survey of popular Views and Recent models', Princeton Studies in International finance, № 42.

Liu, P. (1992). 'Purchasing Power Parity in Latin America: A Cointegration Analysis', Weltwirtschaftliches Archiv, Vol. 128, No 4: 662-680.

Lothian, J. and Taylor, M. (1996). "Real exchange rate behavior: the recent float from the perspective of the past two centuries," Journal of political economy, 104,488-510.

Luukkonen, R., Saikkonen, P., Terasvirta, T. (1988). Testing linearity against smooth transition autoregressive models. Biometrika 75, 491-499.

McNown, R., and M. Wallace, (1989). "National Price Levels, Purchasing Power Parity, and Cointegration: A Test of Four High Inflation Economies," Journal of International Money and Finance, Vol. 8, 533-45.

Michael, P., Nobay, A. R. \& Peel, D. A. (1997). "Transaction costs and nonlinear adjustment in real exchange rates: An empirical investigation." Journal of Political Economy, 105, 862-879.

Obstfeld, M., \& Taylor, A. M. (1997). "Nonlinear aspects of goods-market arbitrage and adjustment: Heckscher's commodity points revisited." Centre for International and Development Economics Research (CIDER) Working Papers C97-088, University of California at Berkeley.

Officier, Laurence H. (1976). "The productivity bias in purchasing power parity : an Econometric Investigation" IMF Staff Papers, Vol. XXIII(3). 545-580.

Oh, K.Y. (1996). 'Purchasing Power Parity and unit root tests using panel data', Journal of International Money and Finance, Vol.15, No. 3: 405-418.

Pigou, A. C. (1920). 'Some Problems in Foreign Exchanges', Economic Journal, 30, 460-472.

Pippenger, P. (2004). "The Modern Theory of the LOP and PPP: Some implications", Departement of economcs, University of California, Santa Barbara, Departemental Working papers, UCSB, $03,04$.

Rogoff, K. (1996) “The purchasing power parity puzzle,” Journal of Economic Literature 34: 647-68.

Sarno, L., \& Taylor, M. P. (2002). "Economics of exchange rates.” Cambridge7 Cambridge University Press.

Sarno, L., and M. P. Taylor (2001). "Purchasing power parity and the real exchange rate." Centre for Economic Policy Research discussion paper No.2913, August, forthcoming International Monetary Fund Staff Papers.

Seabra, F. (1995). 'Short-run exchange rate uncertainty in Latin America', Applied Economics, Vol. 27: 441-450

Sekkioua, H. S. (2005). "Nonlinear adjustment in the forward premium: evidence from a threshold unit root test, International Review of Economics and Finance.

Sercu, P., Uppal, R. and Van Hulle, C. (1995). "The exchange rate in the presence of transactions costs: implications for tests of purchasing power parity," Journal of Finance 50: 1309-1319.

Smallwood. Aaron. D. (2005). "Joint Tests for Long Memory and Non-linearity: The Case of Purchasing Power Parity" Studies in Nonlinear dynamics and Econometrics Vol. 9 No. 2, Article 7.

Stinchcombe M.B., White H. (1998). "Consistent Specification Testing with Nuisance Parameters Present Only Under the Alternative", Econometric Theory, 14, 295-325.

Taylor M.P., Peel D.A. \& Sarno L. (2001). "Nonlinear Mean-Reversion in Exchange Rate Rates: Towards a Solution to the Purchasing Power Parity Puzzles", for coming in International Economic Review. 
Taylor, M. P. (1995). “The Economics of exchange rates.” Journal of Economic Literature, 33, 13-47.

Taylor, M.P. and L. Sarno. (2001). "Nonlinear Mean-Reversion in Real Exchange Rates: Towards a Solution to the Purchasing Power Parity Puzzles," International Economic Review, Vol. 42, 1015-42.

Terasvirta, T. (1994). "Specification, Estimation, and Evaluation of Smooth Transition Autoregressive Models", Journal of the American Statistical Association, Vol. 89, No. 425. pp. 208-218.

Terasvirta, T., (1998) "Modelling economic relationships with smooth transition regressions” In: A. Ullah, D.E.A. Giles (Ed.). Handbook of Applied Economic Statistics. Marcel Dekker, New York, pp. 507-552.

Tong, H. (1990). "Nonlinear Time Series: A Dynamical System Approach” (Oxford: Clarendon Press).

van Dijk, D., Terasvirta, T ,and P.H. Franses. (2002). "Smooth transition autoregressive models - a survey of recent developments," Econometric Reviews, 21, 1-47.

van Dijk, Dick; Franses, Philip Hans; Paap, Richard. (2002). “A nonlinear long memory model, with an application to US unemployment”, Journal of Econometrics Volume: 110, Issue: 2, pp. 135-165.

Viner, J. (1937). 'Studies in the Theories of International trade', Harper and Bros, New York.

Williams, J.C. and B.D. Wright. (1991). "Storage and Commodity Markets” (Cambridge, England: Cambridge University Press).

\section{Notes}

Note 1. The problem of undentified nuisance parameters under the null hypothesis is developed by Ploberger (1994); Hansen (1996) and Stinchcombe \& White (1998).

Note 2. We have used many regressions, and we have found that thee regression with one coefficient only is the one that produces the lowest level of autocorrelation. And still with this level, there is a high autocorrelation.

Table 1. Results for Estimation of ARFIMA (p,d,q) Model

\begin{tabular}{|c|c|c|c|c|}
\hline & Algeria & Egypt & Morocco & Tunisia \\
\hline$\phi_{1}$ & $0.9973[0.0040]$ & $0.9979[0.0025]$ & $0.1304[0.0777]$ & $\begin{array}{c}0.9838 \\
{[0.0148]}\end{array}$ \\
\hline$\phi$ & n.a & n.a & n.a & n.a \\
\hline$\phi$ & n.a & n.a & n.a & n.a \\
\hline$\phi$ & n.a & n.a & n.a & n.a \\
\hline$d$ & $0.2134[0.0578]$ & $0.0262[0.0223]$ & $1[0.0344]$ & $\begin{array}{c}0.0741 \\
{[0.0643]}\end{array}$ \\
\hline$\mu$ & $2.766[3.3346]$ & $1.9122[3.4064]$ & $\begin{array}{c}-0.0782 \\
{[0.0518]}\end{array}$ & $\begin{array}{c}0.1176 \\
{[0.1253]}\end{array}$ \\
\hline Kurtosis & 18,7932 & 82,7698 & 5,8521 & 4,2144 \\
\hline Skewness & 2,6385 & 7,9917 & 0,5358 & 0,5794 \\
\hline Jarque Bera & $4,18 \mathrm{E}+03$ & $1,18 \mathrm{E}+05$ & 164,3785 & 25,3588 \\
\hline $\begin{array}{c}\text { P.val [5] (Q } \\
\text { stat) }\end{array}$ & 0,093 & 0,8284 & 0,9883 & 0,235 \\
\hline $\begin{array}{c}\text { P.val }[10](Q \\
\text { stat) }\end{array}$ & 0,2015 & 0,006 & 0,6213 & 0,3705 \\
\hline $\begin{array}{c}\text { P.val }[20](Q \\
\text { stat) }\end{array}$ & 0,1065 & 0,002 & 0,46 & 0,2607 \\
\hline AIC & $-8,1969$ & $-7,5147$ & $-8,8963$ & $-9,1077$ \\
\hline SIC & $-8,1648$ & $-7,4863$ & $-8,8678$ & $-9,0611$ \\
\hline SSE & 0,0986 & 0,2306 & 0,0576 & 0,0235 \\
\hline
\end{tabular}

Notes: The numerical standard errors are displayed in brackets under the respective coefficients. We used the SIC and AIC, coupled with a criteria that the residuals from the estimated models must be serially uncorrelated to generate the number of AR coefficients. 
Table 2. Tests Results for Linearity

\begin{tabular}{|c|c|c|c|c|}
\hline & Algeria & Egypt & Morocco & Tunisia \\
\hline LM chi2 & 12,1343 & 8,4524 & 5,0994 & 5.5537 \\
\hline p.value chi2 & 0,0023 & 0,0146 & 0,0781 & 0.0622 \\
\hline LM F & 6,2251 & 4,2714 & 2,5564 & 2.7976 \\
\hline p.value F & 0,0022 & 0,0146 & 0,0788 & 0.0632 \\
\hline
\end{tabular}

*.denotes that the country in question is performing a linear model.

Table 3. FI-ESTAR Estimation Results

\begin{tabular}{|c|c|c|c|c|}
\hline & Algeria & Egypt & Morocco & Tunisia \\
\hline mu1 & 0.638 [2.189] & $0.045[0.367]$ & $\begin{array}{c}0.023 \\
{[0.010]}\end{array}$ & $-0.014[0.068]$ \\
\hline phi1(1) & $\begin{array}{c}-0.533 \\
{[5.363]}\end{array}$ & 0.893 [1.311] & $\begin{array}{c}0.441 \\
{[0.597]} \\
\end{array}$ & $0.872[1.006]$ \\
\hline phi1(2) & n.a & n.a & n.a & n.a \\
\hline phi1(3) & n.a & n.a & n.a & n.a \\
\hline phi1(4) & n.a & n.a & $\mathrm{Na}$ & na \\
\hline mu2 & $\begin{array}{c}-0.636 \\
{[2.188]}\end{array}$ & $\begin{array}{c}-0.043 \\
{[0.343]}\end{array}$ & $\begin{array}{c}-0.022 \\
{[0.010]}\end{array}$ & $0.016[0.067]$ \\
\hline phi2(1) & $1.53[5.362]$ & $0.107[1.352]$ & $\begin{array}{c}-0.341 \\
{[0.601]}\end{array}$ & $0.102[1.012]$ \\
\hline phi2(2) & n.a & n.a & n.a & n.a \\
\hline phi2(3) & n.a & n.a & n.a & n.a \\
\hline phi2(4) & n.a & n.a & n.a & na \\
\hline gamma & $\begin{array}{c}29.826 \\
{[102.719]}\end{array}$ & 4.55 [56.693] & $\begin{array}{c}613.423 \\
{[806.553]}\end{array}$ & $\begin{array}{c}50.294 \\
{[345.697]}\end{array}$ \\
\hline c & $0.699[0.256]$ & 0.034 [3.425] & $\begin{array}{c}0.409 \\
{[0.006]}\end{array}$ & $-0.082[0.037]$ \\
\hline$d$ & 0.0018 & 0.00256 & 0.01285 & 1 \\
\hline Kurtosis & 19,68624 & 73,43771 & 6,16848 & 4,20945 \\
\hline Skewness & 2,26762 & 7,06496 & 0,52371 & 0,65636 \\
\hline Jarque Bera & 4460,06657 & 90964,84575 & 195,35035 & 28,14308 \\
\hline P.val [5] (Q stat) & 0,00062 & 0,00538 & 0,97235 & 0,63059 \\
\hline P.val [10] (Q stat) & 0,0021 & 0,00025 & 0,08517 & 0,8536 \\
\hline P.val [20] (Q stat) & 0,00039 & 0,00046 & 0,02453 & 0,82638 \\
\hline AIC & $-8,36697$ & $-7,56321$ & $-8,92625$ & $-9,12115$ \\
\hline SIC & $-8,29187$ & $-7,49646$ & $-8,85939$ & $-9,01104$ \\
\hline SSE & 0,08118 & 0,21351 & 0,0545 & 0,02191 \\
\hline
\end{tabular}

